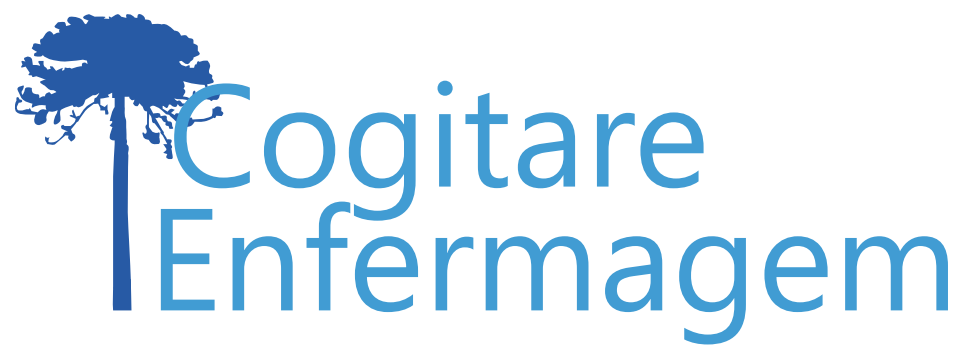

\title{
DIAGNÓSTICOS DE ENFERMAGEM DE PACIENTES PÓS- TRANSPLANTADOS HEPÁTICOS EM ACOMPANHAMENTO AMBULATORIAL
}

Natália de Souza Pires Oliveira1, Thaís Moreira Oliveira², Allana dos Reis Corrêa ${ }^{3}$, Sabrina Daros Tiensoli ${ }^{4}$, Priscila Lara Vieira Bonisson ${ }^{5}$, Gilberto de Lima Guimarães ${ }^{6}$, Bruna Figueiredo Manzo ${ }^{7}$

\begin{abstract}
RESUMO
Objetivo: identificar os diagnósticos de enfermagem de pacientes pós-transplantados hepáticos em acompanhamento ambulatorial.

Método: estudo descritivo realizado entre janeiro e maio de 2015 que avaliou 153 consultas em um ambulatório de Belo Horizonte, Minas Gerais. A elaboração dos diagnósticos de enfermagem seguiu a proposta de Risner, uniformizados seguindo o indicado pelo NANDA-I 2015-2017. Os dados foram analisados pelo programa Statistical Package for Social Sciences.

Resultados: dos pacientes, $102(66,7 \%)$ eram do sexo masculino com mediana de idade de 55 anos. A cirrose por vírus da hepatite $C$ foi a principal indicação de transplante. Foram identificados 11 diagnósticos de enfermagem, sendo os de maior frequência: Risco de infecção, Proteção ineficaz, Risco de glicemia instável, Risco de função hepática prejudicada.

Conclusão: com os diagnósticos de enfermagem identificados, é possível delimitar o perfil das necessidades desses pacientes e proporcionar assistência de enfermagem diferenciada no acompanhamento ambulatorial de pós-transplantados hepáticos.
\end{abstract}

DESCRITORES: Processo de enfermagem; Cuidados de Enfermagem; Diagnóstico de enfermagem; Enfermagem no consultório; Transplante de fígado.

COMO REFERENCIAR ESTE ARTIGO:

Oliveira NSP, Oliveira TM, Corrêa AR, Tiensoli SD, Bonisson PLV, Guimarães GL, et al. Diagnósticos de enfermagem de pacientes pós-transplantados hepáticos em acompanhamento ambulatorial. Cogitare enferm. [Internet]. 2019 [acesso em "colocar data de acesso, dia, mês abreviado e ano"]; 24. Disponível em: http://dx.doi.org/10.5380/ ce.v24i0.59149.

Este obra está licenciado com uma Licença Creative Commons Atribuição 4.0 Internacional.

${ }^{1}$ Enfermeira. Universidade Federal de Minas Gerais. Belo Horizonte, MG, Brasil.

${ }^{2}$ Enfermeira. Mestranda em Enfermagem. Universidade Federal de Minas Gerais. Belo Horizonte, MG, Brasil. 9

${ }^{3}$ Enfermeira. Doutora em Enfermagem. Docente de Enfermagem da Universidade Federal de Minas Gerais. Belo Horizonte, MG, Brasil.

${ }^{4}$ Enfermeira. Doutoranda em Enfermagem. Universidade Federal de Minas Gerais. Belo Horizonte, MG, Brasil.

${ }^{5}$ Enfermeira. Doutoranda em Enfermagem. Universidade Federal de Minas Gerais. Belo Horizonte, MG, Brasil. $\odot$

${ }^{6}$ Enfermeiro. Doutor em Enfermagem. Docente de Enfermagem da Universidade Federal de Minas Gerais. Belo Horizonte, MG, Brasil.

${ }^{7}$ Enfermeira. Doutora em Enfermagem. Docente de Enfermagem da Universidade Federal de Minas Gerais. Belo Horizonte, MG, Brasil. 


\title{
NURSING DIAGNOSES OF POST-LIVER TRANSPLANTATION PATIENTS IN OUTPATIENT FOLLOW-UP
}

\begin{abstract}
Objective: identify the nursing diagnoses of post-liver transplantation patients in outpatient follow-up.

Method: descriptive study developed between January and May 2015, evaluating 153 consultations in an outpatient clinic in Belo Horizonte, Minas Gerais, Brazil. To elaborate the nursing diagnoses, we followed Risner's proposal, standardized according to NANDA-I 20152017. The data were analyzed using Statistical Package for the Social Sciences.

Results: 102 patients (66.7\%) were male with a median age of 55 years. Cirrhosis due to the hepatitis $C$ virus was the main indication for transplantation. We identified eleven nursing diagnoses, the most frequent being: Risk for infection, Ineffective protection, Risk for unstable blood glucose, Risk for impaired liver function.

Conclusion: identifying the nursing diagnoses permits outlining these patients' needs profile and providing differentiated nursing care in the outpatient follow-up of post-liver transplantation patients.
\end{abstract}

DESCRIPTORS: Nursing process; Nursing care; Nursing diagnosis; Office nursing; Liver transplantation.

\section{DIAGNÓSTICOS DE ENFERMERÍA DE PACIENTES TRASPLANTADOS HEPÁTICOS EN SEGUIMIENTO AMBULATORIO}

\section{RESUMEN:}

Objetivo: identificar los diagnósticos de enfermería de pacientes trasplantados hepáticos en seguimiento ambulatorio.

Método: estudio descriptivo desarrollado entre enero y mayo de 2015 que evaluó 153 consultas en un ambulatorio de Belo Horizonte, Minas Gerais, Brasil. En la elaboración de los diagnósticos de enfermería seguimos la propuesta de Risner y los uniformizamos según lo indicado por la NANDA-I 2015-2017. Los datos fueron analizados en el programa Statistical Package for the Social Sciences.

Resultados: de los pacientes, 102 (66,7\%) eran del sexo masculino con edad mediana de 55 años. La cirrosis por el virus de la hepatitis C fue la principal indicación de trasplante. Identificamos 11 diagnósticos de enfermería, siendo los más frecuentes: Riesgo de infección, Protección ineficaz, Riesgo de glicemia instable, Riesgo de función hepática perjudicada. Conclusión: con los diagnósticos de enfermería identificados, es posible delimitar el perfil de las necesidades de esos pacientes y proveer atención de enfermería diferenciada en el seguimiento ambulatorio de trasplantados hepáticos.

DESCRIPTORES: Proceso de Enfermería; Atención de Enfermería; Diagnóstico de enfermería; Enfermería de consulta; Trasplante de hígado. 
Os transplantes são utilizados como recurso terapêutico para diversas doenças crônicas e incapacitantes, visando o aumento de sobrevida dos pacientes ${ }^{(1)}$. O transplante hepático é considerado recurso terapêutico em situação de doença do fígado avançada ou insuficiência hepática aguda, quando não há outros tratamentos clínicos e cirúrgicos disponíveis ${ }^{(2-3)}$. Os avanços com a técnica cirúrgica e a inclusão da terapia com imunossupressores concederam melhora expressiva da sobrevida após o transplante hepático ${ }^{(4-5)}$. É a alternativa terapêutica de maior eficácia no tratamento de hepatopatias graves, neoplasias originadas no fígado e em algumas doenças metabólicas ${ }^{(6)}$.

De acordo com a Associação Brasileira de Transplante de Órgãos, o ano de 2017 pode ser considerado como o ano da retomada do crescimento da doação e do transplante no Brasil ${ }^{(7)}$. Em todo o ano de 2016 ocorreram 1.880 transplantes hepáticos, em 2017 foram realizados 2.109 transplantes hepáticos e especialmente no estado de Minas Gerais efetivaram-se 133 transplantes de fígado no ano de $2017^{(7-8)}$.

No Brasil, o sistema público de saúde oferece acesso gratuito e irrestrito a serviços para toda a população que necessita de transplante de órgãos e tecidos. O país possui um dos maiores programas públicos de transplantes do mundo, com uma política fundamentada nas Leis n. 9.434/1997 e n. 10.211/2001, que trazem como diretrizes a gratuidade da doação, a beneficência em relação aos receptores e a não maleficência em relação aos doadores vivos ${ }^{(9)}$.

Diante da importância de enriquecer a atuação do Enfermeiro no atendimento ao paciente transplantado hepático, estudos são desenvolvidos para reforçar a notoriedade da terapêutica desse transplante, que é alicerçado por políticas públicas consolidadas, e também o interesse das instituições públicas de saúde em prestar esse serviço à população(9-10).

Em ambiente ambulatorial, de acordo com a Resolução do Conselho Federal de Enfermagem n.292/2004, o enfermeiro deve exercer a Sistematização da Assistência de Enfermagem (SAE) nos períodos pré e pós-transplante e realizar consulta de enfermagem com o objetivo de planejar uma assistência integral e sistematizada embasada no Processo de Enfermagem ${ }^{(11)}$.

Durante as consultas de enfermagem, o profissional coleta o histórico do paciente, analisa exames laboratoriais, acompanha a manutenção da alimentação e o controle do peso, orienta quanto ao uso adequado da medicação e seus efeitos colaterais de forma a identificar sinais e sintomas de possível infecção/rejeição(12).

Ao obter essas informações, o enfermeiro utiliza o Processo de Enfermagem para identificar as necessidades individuais do ser humano(13) a fim de reconhecer os problemas de enfermagem que resultam em necessidades de cuidado. Esses problemas são analisados e agrupados para que sejam estabelecidos os Diagnósticos de Enfermagem (DE). Durante as consultas, os DE devem ser levantados para a detecção precoce de complicações e das necessidades humanas afetadas ${ }^{(14)}$.

Para que o planejamento da assistência de enfermagem seja realizado de forma qualificada, é fundamental que se conheça as necessidades de cuidado dos pacientes póstransplantados em acompanhamento ambulatorial. Esta determinação pode contribuir para que os serviços avaliem o processo de atendimento, considerando a diversidade da população ali atendida. Objetivou-se neste estudo identificar os diagnósticos de enfermagem de pacientes pós-transplantados hepáticos em acompanhamento ambulatorial. 
Trata-se de um estudo descritivo, quantitativo, desenvolvido em um ambulatório de referência de um hospital universitário de Belo Horizonte, Minas Gerais. O ambulatório possui equipe multidisciplinar composta por médicos, enfermeiros, assistentes sociais, psicólogos, nutricionistas, educadores físicos e fisioterapeutas. A frequência ao ambulatório pode ser semanal, quinzenal ou mensal, conforme o tempo de transplante e a evolução individual dos pacientes.

A amostra foi composta por conveniência com pacientes pós transplante hepático no período de $1^{\circ}$ de janeiro a 30 de maio de 2015. Elegeu-se como critérios de inclusão pacientes com idade maior ou igual a 18 anos encaminhados ao serviço ambulatorial de transplante de fígado. No período do estudo 155 pacientes compareceram ao ambulatório. Destes, dois não cumpriram o critério de inclusão. Foi considerado critério de exclusão pacientes com idade menor que 18 anos, assim a amostra foi composta por 153 pacientes.

Para a coleta de dados, foi elaborado pelas pesquisadoras um instrumento composto por duas partes, sendo a primeira relativa às características clínicas e sociodemográficas dos pacientes, e a segunda por informações relacionadas à anamnese, abordando as necessidades psicobiológicas, psicossociais, e exame físico, conforme disposto no formulário de consulta de enfermagem utilizado pela instituição, que é pautado na teoria das Necessidade Humanas Básicas ${ }^{(13)}$.

Os pacientes eram conduzidos a um dos consultórios para responder às questões da primeira parte do instrumento. Para a coleta de dados referentes à elaboração dos DE, procedeu-se o acompanhamento e registro das consultas de enfermagem realizadas pelos enfermeiros do ambulatório. Ressalta-se que para este acompanhamento os enfermeiros consentiram e assinaram o TCLE, autorizando a coleta de dados durante as consultas.

Para a caracterização sociodemográfica dos pacientes, foram selecionadas as variáveis: sexo, idade, estado civil e escolaridade. Para o levantamento do perfil clínico, foram coletados: diagnóstico de base; grupo sanguíneo $(A, B, A B$ e $O)$; tempo de transplante (menos de um ano, de um a cinco anos, de seis a 10 anos e 11 anos ou mais); Índice de Massa Corporal (IMC) (<18,5 magro ou baixo peso; 18,5-24,9 normal ou eutrófico; 25,029,9 sobrepeso ou pré-obeso; $30-34,9$ obesidade grau I; $35,0-39,9$ obesidade grau II; $\geq 40$ obesidade grave); ingestão hídrica (menos que um litro por dia, entre um e dois litros por dia e mais que três litros por dia); qualidade de sono (dorme bem, insônia, dorme pouco, dorme com medicação); eliminação vesical (diurese espontânea, oligúria); eliminação gastrintestinal (sem alterações, náusea, constipação e diarreia) e uso de protetor solar (sim ou não).

Para a elaboração dos diagnósticos de enfermagem, utilizou-se o processo de raciocínio diagnóstico de Risner, composto por duas etapas. A primeira, denominada análise, é composta por duas fases: categorização dos dados, organizados de maneira lógica, sistematizada e que podem ser embasados em diferentes modelos conceituais, e identificação de lacunas de dados, fase na qual os dados incompletos são avaliados, podendo ser identificada necessidade de nova coleta de dados, o que, neste estudo, não foi necessário. A segunda etapa, denominada síntese, é composta por três fases: agrupamento de dados relevantes; comparação dos dados agrupados com teorias, modelos e conceitos; e identificação de desvios ou potencialidades de saúde (inferência ou hipótese) ${ }^{(15)}$.

$\mathrm{Na}$ fase de inferência, foram elaboradas as hipóteses diagnósticas, considerando as conclusões esboçadas sobre os problemas do paciente. Após a aplicação do processo de raciocínio diagnóstico, foram elaborados os diagnósticos de enfermagem, utilizando a Taxonomia II da NANDA-I com suas características definidoras, fatores relacionados e fatores de risco.

Os dados foram organizados e tratados estatisticamente pelo programa Statistical Package for Social Science (SPSS) versão 20.0. Para análise das variáveis contínuas realizouse o teste de Shapiro-Wilk para verificação da normalidade e procedeu-se o cálculo da média e mediana. As frequências e proporções foram calculadas para as variáveis categóricas. Ressalta-se que o total dos números de respondentes das variáveis pode variar devido 
à possibilidade de mais de resposta do paciente ou pelo fato do paciente se negar/não saber relatar.

O projeto da pesquisa foi aprovado pelo Comitê de Ética em Pesquisa da Universidade Federal de Minas Gerais parecer $n^{\circ} 925.041$. Foram observados os princípios que regem as pesquisas que envolvem seres humanos previstos na Resolução 466/12 do Conselho Nacional de Saúde(16).

\section{RESULTADOS}

Dos 153 pacientes do estudo, a maioria $102(66,7 \%)$ era do sexo masculino. A idade variou de 19 a 80 anos com mediana de 55 anos. Quanto ao estado civil, 96 (62,7\%) eram casados, $32(20,9 \%)$ solteiros, $12(7,9 \%)$ divorciados e nove $(5,9 \%)$ eram viúvos. Quatro pacientes $(2,6 \%)$ não relataram o estado civil.

Quanto à escolaridade, $61(39,8)$ afirmaram ter ensino médio, $49(32,0 \%)$ pacientes possuíam educação primária, ensino fundamental $20(13,1 \%)$ e $13(8,5 \%)$ ensino superior. Dez pacientes $(6,5 \%)$ não souberam informar o nível de escolaridade.

Houve casos em que um paciente apresentou mais de uma indicação ao transplante. Não foi possível obter a indicação ao transplante apenas de um participante, dessa forma, de 152 pacientes respondentes desta variável obteve-se registro de 198 indicações ao transplante.

A cirrose pós-viral C foi a indicação mais frequente 39 (19,7\%) seguida pela cirrose etanólica $32(16,2 \%)$. A categoria "outros" foi composta pelos diagnósticos presentes em um ou dois casos: glicogenólise tipo I e II, amiloidose, doença policística, cirrose hepatocelular, hepatite autoimune, colangite autoimune, doença de caroli 2 e cirrose biliar secundária. Os dados referentes às indicações e ao tempo de transplante estão descritos na Tabela 1.

Tabela 1 - Indicações ao transplante hepático e tempo de transplante. Belo Horizonte, MG, Brasil, 2015 (continua)

\begin{tabular}{lcc} 
Variáveis & n & $\%$ \\
\hline Indicação ao transplante & $198^{\star}$ & 100 \\
\hline Cirrose pós-viral C & 39 & 19,7 \\
\hline Cirrose etanólica & 32 & 16,2 \\
\hline Cirrose criptogênica & 26 & 13,2 \\
\hline Carcinoma hepatocelular & 26 & 13,2 \\
\hline Cirrose autoimune & 11 & 5,6 \\
\hline Hepatite C & 10 & 5 \\
\hline Colangite esclerosante primária & 8 & 4 \\
\hline Cirrose pós-viral B & 7 & 3,6 \\
\hline Cirrose biliar primária & 6 & 3 \\
\hline Esquistossomose & 6 & 3 \\
\hline Hepatite Fulminante & 4 & 2 \\
\hline Cirrose & 4 & 2 \\
\hline Síndrome de Budd-Chiari & 4 & 2 \\
\hline
\end{tabular}




\begin{tabular}{lcc}
\hline Hepatite B & 3 & 1,5 \\
\hline Outros & 12 & 6 \\
\hline Tempo de transplante & 153 & 100 \\
\hline De um a cinco anos & 62 & 40,5 \\
\hline De seis a 10 anos & 36 & 23,5 \\
\hline Menos de um ano & 34 & 22,2 \\
\hline 11 anos ou mais & 21 & 13,8
\end{tabular}

*Um paciente apresentou mais de uma indicação ao transplante.

Em relação ao tipo sanguíneo, o tipo $O$ foi o mais frequente, 83 pacientes $(54,2 \%)$, seguido pelo tipo A 56 (36,6\%). Apresentaram o tipo B $11(7,2 \%)$ pacientes e o tipo sanguíneo $A B$ dois pacientes $(1,3 \%)$. Apenas um paciente $(0,7)$ não soube responder a tipagem sanguínea. Quanto ao uso de medicamento imunossupressor, constatou-se que $147(96,1 \%)$ pacientes utilizavam o Tacrolimo e seis $(3,9 \%)$ faziam uso da Ciclosporina. As variáveis peso e altura foram utilizadas para cálculo do Índice de Massa Corporal (IMC). A distribuição dos pacientes conforme IMC e os demais dados coletados durante a consulta de enfermagem estão apresentados na Tabela 2.

Tabela 2 - Dados coletados durante a consulta de enfermagem. Belo Horizonte, MG, Brasil, 2015 (continua)

\begin{tabular}{lcc} 
Variáveis & $\mathbf{n}$ & $\%$ \\
\hline Índice de Massa Corporal (IMC) & 153 & 100 \\
\hline Normal ou eutrófico & 59 & 38,6 \\
\hline Sobrepeso ou pré-obeso & 52 & 34 \\
\hline Obesidade grau I & 25 & 16,3 \\
\hline Magro ou baixo peso & 10 & 6,5 \\
\hline Obesidade grau II & 6 & 3,9 \\
\hline Obesidade grave & 1 & 0,7 \\
\hline Qualidade do sono & 153 & 100 \\
\hline Dorme bem & 83 & 54,2 \\
\hline Insônia & 51 & 33,3 \\
\hline Dorme pouco & 10 & 6,6 \\
\hline Dorme com medicação & 9 & 5,9 \\
\hline Eliminação gastrintestinal & 153 & 100 \\
\hline Sem alterações & 149 & 97,3 \\
\hline Constipação & 2 & 1,3 \\
\hline Diarreia & 1 & 0,7 \\
\hline Náusea & 1 & 0,7 \\
\hline Eliminação vesical & 153 & 100 \\
\hline Espontânea & 151 & 98,7 \\
\hline
\end{tabular}




\begin{tabular}{lcc}
\hline Oligúria & 2 & 1,3 \\
\hline Ingestão hídrica & $151^{\star}$ & 100 \\
\hline Mais que três litros & 68 & 45 \\
\hline Entre um e dois litros por dia & 61 & 40,4 \\
\hline Menos que um litro por dia & 22 & 14,6 \\
\hline Utiliza protetor solar & 153 & 100 \\
\hline Sim & 82 & 53,6 \\
\hline Não & 71 & 46,4
\end{tabular}

*percentual válido para os respondentes da variável.

${ }^{\star *}$ categorias definidas de acordo com a Organização Mundial da Saúde.

Foram identificados $11 \mathrm{DE}$, de acordo com a Taxonomia II da NANDA-I, sendo seis reais e cinco diagnósticos de riscos. A Tabela 3 apresenta os DE identificados nos participantes da pesquisa.

Tabela 3 - Diagnósticos de enfermagem segundo a NANDA I 2015-2017. Belo Horizonte, MG, Brasil, 2015

\section{Domínio}

Domínio 11

Segurança/Proteção

\begin{tabular}{|c|c|c|c|}
\hline \multirow[t]{2}{*}{$\begin{array}{l}\text { Domínio } 2 \\
\text { Nutrição }\end{array}$} & $\begin{array}{l}\text { Risco de glicemia instável relacionado a terapia medicamentosa } \\
\text { por imunossupressor }\end{array}$ & 153 & 100 \\
\hline & $\begin{array}{l}\text { Risco de função hepática prejudicada relacionada ao agente } \\
\text { farmacológico }\end{array}$ & 153 & 100 \\
\hline $\begin{array}{l}\text { Domínio } 11 \\
\text { Segurança/Proteção }\end{array}$ & $\begin{array}{l}\text { Proteção ineficaz relacionado a terapia medicamentosa } \\
\text { caracterizado pela deficiência na imunidade }\end{array}$ & 153 & 100 \\
\hline $\begin{array}{l}\text { Domínio } 2 \\
\text { Nutrição }\end{array}$ & $\begin{array}{l}\text { Obesidade relacionada a tempo reduzido de sono caracterizado } \\
\text { IMC > } 30\end{array}$ & 84 & 54,9 \\
\hline $\begin{array}{l}\text { Domínio } 11 \\
\text { Segurança/Proteção }\end{array}$ & $\begin{array}{l}\text { Risco de integridade da pele prejudicada relacionado a } \\
\text { imunodeficiência, agente farmacológico e hidratação }\end{array}$ & 71 & 46,4 \\
\hline $\begin{array}{l}\text { Domínio } 4 \\
\text { Atividade/Repouso }\end{array}$ & $\begin{array}{l}\text { Insônia relacionado a agente farmacológico caracterizado por } \\
\text { estado de saúde comprometido, alteração no padrão de sono e } \\
\text { energia insuficiente }\end{array}$ & 60 & 39,2 \\
\hline $\begin{array}{l}\text { Domínio } 2 \\
\text { Nutrição }\end{array}$ & $\begin{array}{l}\text { Risco de volume de líquidos deficiente relacionado a relato de } \\
\text { ingestão hídrica menor que } 2 \text { litros por dia }\end{array}$ & 22 & 14,4 \\
\hline $\begin{array}{l}\text { Domínio } 4 \\
\text { Atividade/Repouso }\end{array}$ & $\begin{array}{l}\text { Padrão de sono prejudicado relacionado a padrão de sono não } \\
\text { restaurador e caracterizado por alteração do padrão no sono e } \\
\text { insatisfação com o sono }\end{array}$ & 10 & 6,5 \\
\hline \multirow[t]{2}{*}{$\begin{array}{l}\text { Domínio } 3 \\
\text { Eliminação e troca }\end{array}$} & $\begin{array}{l}\text { Constipação relacionada a agentes farmacológicos, ingestão } \\
\text { insuficiente de líquidos caracterizado por redução da frequência } \\
\text { das fezes }\end{array}$ & 2 & 1,3 \\
\hline & $\begin{array}{l}\text { Diarreia relacionado a regime de tratamento caracterizado por } \\
\text { urgência intestinal }\end{array}$ & 1 & 0,7 \\
\hline
\end{tabular}

\section{Diagnósticos de Enfermagem}

Risco de infecção relacionado à imunossupressão

n $\%$

153100


A predominância do sexo masculino nos pacientes transplantados hepáticos também ocorreu em outros estudos realizados no Brasil, como nos estados do Ceará e Rio de Janeiro, com frequências de $80,0 \%$ e $61,0 \%$ respectivamente ${ }^{(17-18)}$. Pesquisa realizada em Portugal também encontrou o sexo masculino como maioria dos pacientes transplantados hepáticos ${ }^{(2)}$.

A idade dos pacientes transplantados encontrada no presente estudo também foi relatada nos estudos supracitados, sendo que, no Ceará, $47 \%$ dos pacientes estavam na faixa etária entre 40-59 anos e em Porto, a média de idade foi de 51 anos ${ }^{(2,17)}$. O estado civil com maior frequência foi casado, dado semelhante encontrado em outro estudo, no qual $76,7 \%$ dos pacientes eram casados ou possuíam união estável(19).

O tempo médio de estudo predominante na amostra foi de 9 a 11 anos, o que pode contribuir para a adesão do paciente ao seu tratamento. Pesquisa realizada com pacientes pós transplantados hepáticos encontrou como resultado de nível de escolaridade 10-12 anos de estudo $(37,3 \%)^{(19)}$, dado que corrobora com a presente pesquisa. Por outro lado, estudo realizado no centro de transplante do Porto em Portugal, que investigou o estilo de gestão do regime terapêutico das pessoas submetidas ao transplante hepático, encontrou cinco anos de estudo em $77,3 \%$ da amostra ${ }^{(2)}$.

As principais indicações ao transplante hepático, cirrose pós viral C, cirrose etanólica e cirrose criptogênica, são identificadas também como principais causas de transplante hepático no Brasil(19-20). Segundo recomendações da Associação Americana Para o Estudo de Doenças do Fígado, o transplante hepático é uma terapia efetiva para a cirrose criptogênica e nos Estado Unidos, a cirrose por vírus da hepatite $C$ também é a indicação mais comum ao transplante hepático(6).

Ao comparar a tipagem sanguínea da amostra do estudo com a dos doadores de fígado do ano de 2017 em Minas Gerais, foi encontrado que o índice de transplantes em pacientes com tipagem sanguínea $A$ e $O$ supera as do tipo $B$ e $A B^{(8)}$, dado que corrobora o que foi encontrado nesse estudo e que torna uma preocupação para os pacientes que aguardam por um órgão compatível na fila de espera.

O Tacrolimo é o medicamento de eleição em quase $90 \%$ dos doentes submetidos a transplante hepático, resultando um aumento considerável na sua utilização desde $1990^{(6)}$. O Tacrolimo apresenta melhor taxa de sobrevida do enxerto, menor incidência de rejeição celular aguda e menor toxicidade renal, em comparação com a ciclosporina nos primeiros dois anos pós-transplante( ${ }^{(3,10)}$.

Foram identificados 11 diagnósticos de enfermagem: seis reais e cinco de risco. Os diagnósticos Risco de infecção e Proteção ineficaz se definem, respectivamente, como a vulnerabilidade à invasão e multiplicação de organismos patogênicos, que pode comprometer a saúde e diminuir a capacidade de proteger-se de ameaças internas ou externas como doenças ou lesões ${ }^{(14)}$. As complicações infecciosas são uma das principais causas de morbimortalidade nos pacientes pós-transplantados, estima-se que dois terços dos indivíduos submetidos a transplante desenvolverão uma infecção após o transplante ${ }^{(21)}$.

O risco de glicemia instável esteve relacionado ao uso de imunossupressores, que é um fator de risco para o desenvolvimento de Diabetes Melittus pós-transplante. O Tacrolimo tem menor incidência de hiperlipidemia, hipertensão e problemas estéticos, porém é mais provável do que a ciclosporina para induzir diabetes pós-transplante e neurotoxicidade $\mathrm{e}^{(3,10,21)}$.

Alguns fatores contribuem para os pós-transplantados hepáticos terem ganho de peso acima do normal, associados ao uso dos medicamentos imunossupressores, como a dislipidemia e a hiperglicemia ou diabetes pós-transplante ${ }^{(10)}$. Sendo assim, a equipe multiprofissional deve promover programas de prevenção do ganho de peso excessivo durante o acompanhamento desses pacientes ${ }^{(22)}$. 
O risco de função hepática prejudicada é definido como a vulnerabilidade à diminuição na função hepática que pode comprometer à saúde ${ }^{(14)}$. Embora a imunossupressão baseada no Tacrolimo seja atualmente aceita como a principal terapia, em vários centros de transplante em todo o mundo, efeitos colaterais associados ao seu uso às vezes são encontrados após transplante de órgão sólido, como a neurotoxicidade, nefrotoxicidade e hipertensão(10), o que pode comprometer a função hepática do paciente pós transplantado.

Acredita-se que o Risco de volume de líquidos deficientes esteve relacionado à baixa ingestão de água, o que pode trazer consequências como boca seca, fadiga, tontura, indisposição e desatenção(23). Estudo acerca do transplante renal ${ }^{(24)}$ também encontrou como necessidade humana básica alterada nos transplantados a hidratação. A recomendação da ingestão de água deve ser embasada de forma individual, com ingestão diária adequada, de forma a minimizar os riscos para a saúde ${ }^{(23)}$.

Quanto aos DE de Insônia e Padrão de sono prejudicado, de acordo com uma revisão sistemática ${ }^{(25)}$ o sono é necessidade física para boa saúde e vida saudável, na qual há restauração física que protege o ser do desgaste natural das horas acordadas. Dormir é tão importante para conservar a saúde quanto ter alimentação saudável e praticar exercício físico regularmente ${ }^{(25)}$.

O risco de integridade da pele prejudicada é definido por vulnerabilidade à alteração na epiderme e/ou derme, que pode comprometer a saúde ${ }^{(14)}$. Estudo (26) afirma que a pele é o órgão no qual mais frequentemente se desenvolvem neoplasias em indivíduos transplantados. O aumento desse risco advém da combinação da vigilância imunológica reduzida, que facilita a sobrevivência e proliferação de células anómalas, com os efeitos carcinogênicos diretos dos agentes imunossupressores. Por isso, o uso de protetor solar deve ser encorajado ${ }^{(26)}$ pelo enfermeiro durante as consulta de enfermagem.

Sobre os DE Constipação e Diarreia, uma pesquisa concluiu que o uso dos medicamentos da classe inibidores de calcineurina, Ciclosporina e Tacrolimo, podem causar, dentre outros efeitos, a diarreia(10). Pesquisas apontam que essas alterações gastrintestinais podem estar presentes em pacientes candidatos a transplante de fígado( ${ }^{(27)}$ e também em pacientes em pós-transplante imediato ${ }^{(28)}$.

Acredita-se que a identificação de DE durante o acompanhamento ambulatorial dos pacientes pós transplantados hepáticos seja capaz de otimizar o cuidado, fortalecer a construção de conhecimento e o compartilhamento de informações, para promover melhor qualidade de vida pós-transplante. O trabalho da equipe multiprofissional possibilita o fornecimento de orientações acerca da adaptação ao novo órgão, alimentação, controle glicêmico, pressão arterial, peso, novo estilo de vida e o uso contínuo da medicação(9).

Pode-se apontar como limitação do estudo a descontinuidade do acompanhamento das demais consultas de enfermagem realizadas pelos pacientes incluídos no estudo. Ademais, os resultados são referentes aos atendimentos locais e por isso a possibilidade de análise conclusiva se restringe somente à população atendida no referido ambulatório.

\section{CONCLUSÃO}

Foram identificados 11 diagnósticos de enfermagem, seis reais e cinco de risco, sendo os de maior frequência: Risco de infecção, Proteção ineficaz, Risco de glicemia instável, Risco de função hepática prejudicada, Obesidade e Risco de volume de líquidos deficiente.

Entende-se que este estudo atingiu o objetivo proposto, pois identificou os diagnósticos de enfermagem dos pacientes pós-transplantados hepáticos em acompanhamento ambulatorial. O enfermeiro também é ator na educação em saúde dos pacientes e, por meio dos DE identificados, é possível a construção de estratégias para fornecer ao paciente medidas para um estilo de vida saudável e controle das funções 
adaptativas, relacionadas aos novos desafios de vida pós-transplante.

O levantamento dos DE e o conhecimento das características epidemiológicas e clínicas da população atendida no pós-transplante são ferramentas fundamentais para que o enfermeiro possa planejar e implementar ações direcionadas, individualizadas e mais específicas, que contemplem não só a necessidade saúde/doença apresentada pelo paciente, mas que previnam a ocorrência de agravos e que impulsionem a mudança de hábitos desses pacientes a fim de se obter uma melhor qualidade de vida.

Consideram-se relevantes os dados obtidos neste estudo, porém, é importante identificar algumas limitações, como o fato dos DE ainda não serem utilizados durante todas as consultas de enfermagem no serviço estudado; o formulário de coleta de dados poderia abordar outras variáveis que incluísse também os familiares e comunidade em que o pós-transplantado se insere, para possibilitar possíveis intervenções na realidade de maneira integral.

\section{REFERÊNCIAS}

1. Barreto BS, Santana RJB, Nogueira EC, Fernandez BO, Brito FPG. Fatores relacionados à não doação de órgãos de potenciais doadores no estado de Sergipe, Brasil. Rev. Bras. Pesqui. Saúde. [Internet]. 2016 [acesso em 22 mar 2018]; 18(3). Disponível em: http://periodicos.ufes.br/RBPS/article/view/15741/10888.

2. Mota L, Bastos FS, Brito MAC. A pessoa submetida a transplante de fígado: caracterização do estilo de gestão do regime terapêutico. Rev Enferm Ref. [Internet]. 2017 [acesso em 01 abr 2018]; (13). Disponível em: https://doi.org/10.12707/RIV17006.

3. Moini M, Schilsky ML, Tichy EM. Review on immunosuppression in liver transplantation. World J. Hepatol. [Internet]. 2015 [acesso em 25 mar 2018]; 7(10). Disponível em: https://doi.org/10.4254/wjh. v7.i10.1355.

4. Meirelles Júnior RF, Salvalaggio P, Rezende MB, Evangelista AS, Guardia BD, Matielo CEL, et al. Liver transplantation: history, outcomes and perspectives. Einstein. [Internet]. 2015 [acesso em 13 abr 2018]; 13(1). Disponível em: https://doi.org/10.1590/S1679-45082015RW3164.

5. Yang LS, Shan LL, Saxena A, Morris DL. Liver transplantation: a systematic review of long-term quality of life. Liver Int. [Internet]. 2014 [acesso em 22 mar 2018]; 34(9). Disponível em: https://doi.org/10.1111/ liv.12553.

6. Martin P, Dimartini A, Feng S, Brown R, Fallon M. Evaluation for liver transplantation in adults: 2013 practice guideline by the American Association for the Study of Liver Diseases and the American Society of Transplantation. Hepatology [Internet]. 2014 [acesso em 02 abr 2018]; 59(3). Disponível em: https:// www.aasld.org/sites/default/files/guideline documents/Evaluation for\%20LT in Adults hep26972 0.pdf.

7. Associação Brasileira de Transplante de Órgãos (ABTO). Dimensionamento dos Transplantes no Brasil e em cada estado (2009-2016). Reg. Bras. Transp [Internet]. 2016. [Acesso em 20 mar 2018]; 22(4).

Disponível em: www.abto.org.br/abtov03/Upload/file/RBT/2016/RBT2016-leitura.pdf.

8. Associação Brasileira de Transplante de Órgãos (ABTO). Dimensionamento dos Transplantes no Brasil e em cada estado (2010-2017). Reg. Bras. Transp [Internet]. 2017. [Acesso em 20 mar 2018]; 23(4).

Disponível em: http://www.abto.org.br/abtov03/Upload/file/RBT/2017/rbt-imprensa-leitura-compressed. pdf.

9. Ferrazzo S, Vargas MAO, Gomes DC, Gelbcke FL, Hammerschimidt KSA, Lodeyro CF. Serviço especializado em transplante hepático em um hospital universitário: um estudo de caso. Texto contexto - enferm. [Internet]. 2017 [acesso em 21 mar 2018]; 26(2). Disponível em: http://dx.doi.org/10.1590/0104$\underline{07072017002630015 .}$

10. Sá RC, Soares CRS. Terapia imunossupressora no transplante de fígado: contribuição para a enfermagem. Rev. Aten. Saúde [Internet]. 2016 [acesso em 13 abr 2018]; 14(50). Disponível em: http:// 
seer.uscs.edu.br/index.php/revista ciencias saude/article/view/3992/0.

11. Conselho Federal de Enfermagem. Resolução n. 292, de 07 junho 2004. Normatiza a atuação do Enfermeiro na Captação e Transplante de Órgãos e Tecidos. Rio de Janeiro: COFEN; 2004.

12. Silva AES, Pontes UO, Genzini T, Prado PR, Amaral TLM. Revisão integrativa sobre o papel do enfermeiro no pós-transplante renal. Cogitare enferm. [Internet]. 2014 [acesso em 20 fev 2018]; 19(3) Disponível em: http://dx.doi.org/10.5380/ce.v19i3.34414.

13. Horta WA. Processo de Enfermagem. São Paulo; EPU; 1979.

14. NANDA I. Diagnósticos de enfermagem da NANDA: definições e classificação - 2015 - 2017. Porto Alegre: Artmed; 2015.

15. Bertoncello KCG, Sávio B, Ferreira LN, do Nascimento ERP. Diagnósticos e propostas de intervenções de enfermagem aos pacientes em pós operatório imediato de cirurgia eletiva. Cogitare enferm. [Internet]. 2014 [acesso em 02 abr 2018]; 19(3). Disponível em: http://dx.doi.org/10.5380/ce.v19i3.33676.

16. Ministério da Saúde (BR). Conselho Nacional de Saúde. Diretrizes e normas regulamentadoras de pesquisa envolvendo seres humanos. Resolução n. 466, de 12 de dezembro de 2012. Brasília; 2012.

17. Aguiar MIF, Braga VAB, Garcia JHP, Lima CA, Almeida PC, Souza AMA, et al. Quality of life in liver transplant recipients and the influence of sociodemographic factors. Rev. Esc. Enferm. USP. [Internet]. 2016 [acesso em 03 abr 2018]; 50(3) Disponível em: http://dx.doi.org/10.1590/S0080623420160000400006 .

18. Morais EN, Conrad D, Machado GC, Abreu MO, Mattos EM, da Cruz SAC. Complicações pósoperatórias do transplante hepático: evidências para otimização da assistência de enfermagem. Rev. pesqui. cuid. fundam. [Internet]. 2017 [acesso em 29 mar]; 9(4) Disponível em: http://dx.doi. org/10.9789/2175-5361.2017.v9i4.999-1007.

19. Aguiar MIF, Braga VAB, Almeida PC, Garcia JHP, Lima CA. Gravidade da doença hepática e qualidade de vida no transplante de fígado. Acta paul. enferm. [Internet]. 2016 [acesso 15 abr 2018]; 29(1).

Disponível em: http://dx.doi.org/10.1590/1982-0194201600015.

20. Oliveira PC, Paglione HB, Mucci S, Silva e Silva V, Schirmer J, Roza B de A. Avaliação do conhecimento dos candidatos a transplante de fígado. Rev enferm UFSM [Internet]. 2016 [acesso em 20 abr 2018]; 6(4). Disponível em: http://dx.doi.org/10.5902/2179769223175.

21. European Association for the Studyofthe Liver. EASL Clinical Practice Guidelines: Liver transplantation. J Hepatol. [Internet]. 2016 [acesso em 22 de abr 2018]; 64(2). Disponível em: http://dx.doi.org/10.1016/j. jhep.2015.10.006.

22. Anastácio LR, Pereira MCA, Vilela EG, Lima AS, Correira MITD. Excesso de peso em pacientes submetidos ao transplante hepático. Rev Col Bras Cir. [Internet]. 2013 [acesso em 13 mar 2018]; 40(6). Disponível em: http://dx.doi.org/10.1590/S0100-69912013000600014.

23. Azevedo PS, Pereira FWL, Paiva SAR. Água, Hidratação e Saúde. Soc Bras Aliment e Nutr. 2016; 1-16.

24. Souza TL, Trindade TRO, Mendonça AEO, Silva RAR. Necessidades humanas básicas alteradas em pacientes pós- transplante renal : estudo transversal. Online Braz. j. nurs. [Internet]. 2014 [acesso em 20 abr 2018]; 15(2). Disponível em: http://dx.doi.org/10.17665/1676-4285.20165253.

25. Certo, A, Gomes, MJ, Nascimento, CEP. Qualidade do sono do doente em contexto médico cirúrgico. $2{ }^{\circ}$ Congresso Internacional "Novos Olhares na Saúde"; 2014 Jun. p. 465-72; Chaves, Portugal. Chaves: Escola Superior de Enfermagem; 2014.

26. Sanches MM, Travassos AR, Soares-de-almeida L. The relationship between immunodepression and the development of skin cancer. Acta Med. Port. [Internet]. 2017 [acesso em 11 mar 2018]; 30(1). Disponível em: http://dx.doi.org/10.20344/amp.7997. 
27. Mendes KDS, Lopes NLC, Fabbris MA, Castro-e-Silva Júnior O, Galvão CM. Caracterização sociodemográfica e clínica de candidatos a transplante de fígado. Acta paul. enferm. [Internet]. 2016 [acesso em 17 mar 2018]; 29(2). Disponível em: http://dx.doi.org/10.1590/1982-0194201600019.

28. Barbosa AS, Studart RMB. Nursing diagnostics in patients hospitalized in a high complexity postoperative unit. Rev enferm UFPI. [Internet]. 2017 [acesso em 24 mar 2018]; 6(3). Disponível em: https://doi.org/10.26694/reufpi.v6i3.5893.

Recebido: $26 / 04 / 2018$

Finalizado: 28/01/2019

Autor Correspondente:

Thaís Moreira Oliveira

Universidade Federal de Minas Gerais

R. Ressurreição, 356 - 30820-170 - Belo Horizonte, MG, Brasil

E-mail: thaismo18@gmail.com

Contribuição dos autores:

Contribuições substanciais para a concepção ou desenho do estudo; ou a aquisição, análise ou interpretação de dados do estudo - SDT

Elaboração e revisão crítica do conteúdo intelectual do estudo - SDT, PLVB, GLG, BFM

Aprovação da versão final do estudo a ser publicado - NSPO, TMO, ARC, SDT, PLVB, GLG, BFM

Responsável por todos os aspectos do estudo, assegurando as questões de precisão ou integridade de qualquer parte do estudo - NSPO, TMO, ARC 